\title{
Characteristics and outcomes of 627044 COVID-19 patients with and without obesity in the United States, Spain, and the United Kingdom
}

Martina Recalde MPH ${ }^{1,2 *}$, Elena Roel MD MPH ${ }^{1 *}$, Andrea Pistillo MSc ${ }^{1}$, Anthony G. Sena BA $^{3,4}$, Albert Prats-Uribe MD MPH ${ }^{5}$, Waheed-Ul-Rahman Ahmed ${ }^{6,7}$, Heba Alghoul MD ${ }^{8}$, Thamir M Alshammari PhD', Osaid Alser MD ${ }^{10}$, Carlos Areia MSc ${ }^{11}$, Edward Burn PhD ${ }^{1,5}$, Paula Casajust $\mathrm{MSc}^{12}$, Dalia Dawoud $\mathrm{PhD}^{13}$, Scott L. DuVall PhD ${ }^{14,15}$, Thomas Falconer MS ${ }^{16}$, Sergio Fernández-Bertolín BSc ${ }^{1}$, Asieh Golozar MD PhD MHS MPH ${ }^{17,} 18$, Mengchun Gong MD ${ }^{19}$, Lana Yin Hui Lai PhD ${ }^{20}$, Jennifer C.E. Lane MRCS ${ }^{5}$, Kristine E. Lynch PhD ${ }^{14,15}$, Michael E. Matheny MD MPH ${ }^{21,22}$, Paras P Mehta $\mathrm{BA}^{23}$, Daniel R. Morales MD PhD ${ }^{24}$, Karthik Natarjan $\mathrm{PhD}^{16,25}$, Fredrik Nyberg MD $\mathrm{PhD}^{26}$, Jose D. Posada PhD ${ }^{27}$, Christian G. Reich MD PhD ${ }^{28}$, Lisa M. Schilling MD MSPH ${ }^{29}$, Karishma Shah MBBS ${ }^{6}$, Nigam H. Shah MBBS PhD ${ }^{27}$, Vignesh Subbian $\mathrm{PhD}^{30}$, Lin Zhang MD PhD ${ }^{31,32}$, Hong Zhu PhD ${ }^{33,34}$, Patrick Ryan $\mathrm{PhD}^{3,16}$, Daniel Prieto-Alhambra Prof ${ }^{5}$, Kristin Kostka MPH ${ }^{28_{* *}}$, Talita Duarte-Salles $\mathbf{P h D}^{1}{ }^{1 * *}$

*Joint first authors

**Joint last authors

1. Fundació Institut Universitari per a la recerca a l'Atenció Primària de Salut Jordi Gol i Gurina (IDIAPJGol), Barcelona, Spain

2. Universitat Autònoma de Barcelona, Spain

3. Janssen Research \& Development, Titusville, NJ, USA

4. Department of Medical Informatics, Erasmus MC, Rotterdam, The Netherlands

5. Centre for Statistics in Medicine, NDORMS, University of Oxford

6. Nuffield Department of Orthopaedics, Rheumatology, and Musculoskeletal Sciences, University of Oxford, Botnar Research Centre, Windmill Road, Oxford, OX3 7LD, UK.

7. College of Medicine and Health, University of Exeter, St Luke's Campus, Heavitree Road, Exeter, EX1 2LU, UK.

8. Faculty of Medicine, Islamic University of Gaza, Palestine

9. Medication Safety Research Chair, King Saud University

10. Massachusetts General Hospital, Harvard Medical School, Boston, 02114, Massachusetts, USA

11. Nuffield Department of Clinical Neurosciences, University of Oxford, UK

12. Real-World Evidence, Trial Form Support, Barcelona, Spain

13. Cairo University, Faculty of Pharmacy, Cairo, Egypt

14. VA Informatics and Computing Infrastructure, VA Salt Lake City Health Care System, Salt Lake City, UT, USA

15. Department of Internal Medicine, University of Utah School of Medicine, Salt Lake City, UT,

W囚fE: This preprint reports new research that has not been certified by peer review and should not be used to guide clinical practice. 
medRxiv preprint doi: https://doi.org/10.1101/2020.09.02.20185173; this version posted September 3, 2020. The copyright holder for this preprint (which was not certified by peer review) is the author/funder, who has granted medRxiv a license to display the preprint in

It is made available under a CC-BY-NC-ND 4.0 International license.

16. Department of Biomedical Informatics, Columbia University, New York, NY, USA

17. Department of Epidemiology, Johns Hopkins School of Public, Baltimore MD, USA

18. Pharmacoepidemiology, Regeneron Pharmaceuticals, NY, US

19. DHC Technologies co, ltd., Beijing, China

20. Division of Cancer Sciences, School of Medical Sciences, University of Manchester

21. Tennessee Valley Healthcare System, Veterans Affairs Medical Center, Nashville, TN, USA

22. Department of Biomedical Informatics, Vanderbilt University Medical Center, Nashville, TN, USA

23. College of Medicine, The University of Arizona, Tucson, AZ, USA

24. Division of Population Health and Genomics, University of Dundee, UK

25. New York-Presbyterian Hospital, New York, NY, US

26. School of Public Health and Community Medicine, Institute of Medicine, Sahlgrenska

Academy, University of Gothenburg, Gothenburg, Sweden

27. Department of Medicine, Stanford University, Palo Alto, California, USA

28. Real World Solutions, IQVIA, Cambridge, MA, USA

29. Data Science to Patient Value Program, Department of Medicine, University of Colorado Anschutz Medical Campus

30. College of Engineering, The University of Arizona, Tucson, AZ, USA

31. School of Population Medicine and Public Health, Chinese Academy of Medical Sciences \& Peking Union Medical College

32. Melbourne School of Population and Global Health, The University of Melbourne

33. Institute of Health Management, Southern Medical University, Guangzhou, China

34. Nanfang Hospital, Southern Medical University, Guangzhou, China

Corresponding author: Talita Duarte-Salles

Fundació Institut Universitari per a la recerca a l'Atenció Primària de Salut Jordi Gol i Gurina (IDIAPJGol)

Gran Via Corts Catalanes, 587 àtic

08007 Barcelona - Spain

Tel: +34935824342

Email: tduarte@idiapjgol.org

Key Words: COVID-19; obesity; hospital admission; case-fatality rate

Abbreviations: ARDS: Acute Respiratory Distress Syndrome; BMI: Body Mass Index; CDM: Common Data Model; COVID-19: Coronavirus disease 2019; CPRD: Clinical Practice Research Datalink; CUIMC: Columbia University Irving Medical Center; EHR: Electronic Health Record; IRB: Institutional Review Board; OHDSI: Observational Health Data Sciences and Informatics; OMOP: Observational Medical Outcomes Partnership; SARS-CoV-2: severe acute respiratory syndrome coronavirus 2; SIDIAP: Information System for Research in Primary Care; SNOMED: Systematized Nomenclature of Medicine; STARR-OMOP: Stanford Medicine Research Data 
medRxiv preprint doi: https://doi.org/10.1101/2020.09.02.20185173; this version posted September 3, 2020. The copyright holder for this preprint (which was not certified by peer review) is the author/funder, who has granted medRxiv a license to display the preprint in It is made available under a CC-BY-NC-ND 4.0 International license

Repository; UK: United Kingdom; US: United States; VA-OMOP: United States Department of Veterans Affairs; WHO: World Health Organization 
medRxiv preprint doi: https://doi.org/10.1101/2020.09.02.20185173; this version posted September 3, 2020. The copyright holder for this preprint (which was not certified by peer review) is the author/funder, who has granted medRxiv a license to display the preprint in

It is made available under a CC-BY-NC-ND 4.0 International license .

\section{Abstract}

Background: COVID-19 may differentially impact people with obesity. We aimed to describe and compare the demographics, comorbidities, and outcomes of obese patients with COVID-19 to those of non-obese patients with COVID-19, or obese patients with seasonal influenza.

Methods: We conducted a cohort study based on outpatient/inpatient care, and claims data from January to June 2020 from the US, Spain, and the UK. We used six databases standardized to the OMOP common data model. We defined two cohorts of patients diagnosed and/or hospitalized with COVID-19. We created corresponding cohorts for patients with influenza in 2017-2018. We followed patients from index date to 30 days or death. We report the frequency of sociodemographics, prior comorbidities, and 30-days outcomes (hospitalization, events, and death) by obesity status.

Findings: We included 627044 COVID-19 (US: 502 650, Spain: 122 058, UK: 2336) and 4549 568 influenza (US: 4431 801, Spain: 115 224, UK: 2543) patients. The prevalence of obesity was higher among hospitalized COVID-19 (range: 38\% to 54\%) than diagnosed COVID-19 (30\% to $47 \%$ ), or diagnosed (15\% to $47 \%$ ) or hospitalized (27\% to $48 \%$ ) influenza patients. Obese hospitalized COVID-19 patients were more often female and younger than non-obese COVID-19 patients or obese influenza patients. Obese COVID-19 patients were more likely to have prior comorbidities, present with cardiovascular and respiratory events during hospitalization, require intensive services, or die compared to non-obese COVID-19 patients. Obese COVID-19 patients were more likely to require intensive services or die compared to obese influenza patients, despite presenting with fewer comorbidities.

Interpretation: We show that obesity is more common amongst COVID-19 than influenza patients, and that obese patients present with more severe forms of COVID-19 with higher hospitalization, intensive services, and fatality than non-obese patients. These data are instrumental for guiding preventive strategies of COVID-19 infection and complications. 
medRxiv preprint doi: https://doi.org/10.1101/2020.09.02.20185173; this version posted September 3, 2020. The copyright holder for this preprint (which was not certified by peer review) is the author/funder, who has granted medRxiv a license to display the preprint in

It is made available under a CC-BY-NC-ND 4.0 International license .

\section{Funding}

The European Health Data \& Evidence Network has received funding from the Innovative Medicines Initiative 2 Joint Undertaking (JU) under grant agreement No 806968. The JU receives support from the European Union's Horizon 2020 research and innovation programme and EFPIA. This research received partial support from the National Institute for Health Research (NIHR) Oxford Biomedical Research Centre (BRC), US National Institutes of Health, US Department of Veterans Affairs, Janssen Research \& Development, and IQVIA. The University of Oxford received funding related to this work from the Bill \& Melinda Gates Foundation (Investment ID INV-016201 and INV-019257). APU has received funding from the Medical Research Council (MRC) [MR/K501256/1, MR/N013468/1] and Fundación Alfonso Martín Escudero (FAME) (APU). VINCI [VA HSR RES 13-457] (SLD, MEM, KEL). JCEL has received funding from the Medical Research Council (MR/K501256/1) and Versus Arthritis (21605). No funders had a direct role in this study. The views and opinions expressed are those of the authors and do not necessarily reflect those of the Clinician Scientist Award programme, NIHR, Department of Veterans Affairs or the United States Government, NHS, or the Department of Health, England. 
medRxiv preprint doi: https://doi.org/10.1101/2020.09.02.20185173; this version posted September 3, 2020. The copyright holder for this preprint (which was not certified by peer review) is the author/funder, who has granted medRxiv a license to display the preprint in

It is made available under a CC-BY-NC-ND 4.0 International license.

\section{Research in context}

\section{Evidence before this study}

Previous evidence suggests that obese individuals are a high risk population for COVID-19 infection and complications. We searched PubMed for articles published from December 2019 until June 2020, using terms referring to SARS-CoV-2 or COVID-19 combined with terms for obesity. Few studies reported obesity and most of them were limited by small sample sizes and restricted to hospitalized patients. Further, they used different definitions for obesity (i.e. some reported together overweight and obesity, others only reported obesity with BMI $>40 \mathrm{~kg} / \mathrm{m}^{2}$ ). To date, no study has provided detailed information on the characteristics of obese COVID-19 patients, such as the prevalence of comorbidities or COVID-19 related outcomes. In addition, despite the fact that COVID-19 has been often compared to seasonal influenza, there are no studies assessing whether obese patients with COVID-19 differ from obese patients with seasonal influenza.

\section{Added value of this study}

We report the largest cohort of obese patients with COVID-19 and provide information on more than 29000 aggregate characteristics publicly available. Our findings were consistent across the participating databases and countries. We found that the prevalence of obesity is higher among COVID-19 compared to seasonal influenza patients. Obese patients with COVID-19 are more commonly female and have worse outcomes than non-obese patients. Further, they have worse outcomes than obese patients with influenza, despite presenting with fewer comorbidities.

\section{Implications of all the available evidence}

Our results show that individuals with obesity present more comorbidities and worse outcomes for COVID-19 than non-obese patients. These findings may be useful in guiding clinical practice and future preventative strategies for obese individuals, as well as provide useful data to support subsequent association studies focussed on obesity and COVID-19. 
medRxiv preprint doi: https://doi.org/10.1101/2020.09.02.20185173; this version posted September 3, 2020. The copyright holder for this preprint (which was not certified by peer review) is the author/funder, who has granted medRxiv a license to display the preprint in

It is made available under a CC-BY-NC-ND 4.0 International license.

\section{Introduction}

Obesity is associated with increased mortality and is a well-known risk factor of chronic conditions, such as diabetes, hypertension, cardiovascular disease and, cancer. ${ }^{1}$ Due to its proinflammatory state that impairs the immune response, obesity has also been related to increased risk of viral infections, including seasonal influenza. ${ }^{2}$

The novel coronavirus disease 2019 (COVID-19), caused by the severe acute respiratory syndrome coronavirus 2 (SARS-CoV-2), has been compared to seasonal influenza in terms of symptoms and complications. ${ }^{3}$ Both viruses cause respiratory tract infection with clinical manifestations ranging from asymptomatic/mild symptoms to severe illness requiring intensive services. Partly due to its similarities with influenza, people with obesity were soon labelled as "at-risk" individuals. ${ }^{4}$ Recent studies have found that obesity is common among severe and fatal COVID-19 cases. $^{5-8}$ In hospitalized cohorts from the United States (US), obesity prevalence in COVID-19 cases ranges from 40 to $50 \%,{ }^{9-11}$ while lower prevalence has been reported in non-hospitalized cases. A primary care study from Spain found that $20 \%$ of COVID-19 cases were obese, ${ }^{12}$ while in a populationbased study from Denmark only $9 \%$ were obese. ${ }^{13}$

Since obesity is a worldwide public health priority, granular information on obese patients with COVID-19 is needed to guide preventive strategies. ${ }^{14}$ In this study, we aimed to describe and compare the demographics, comorbidities, and outcomes of obese patients with COVID-19 to those of 1) non-obese patients with COVID-19, and 2) obese patients with seasonal influenza, among inpatient or outpatient settings.

\section{Methods}

\section{Study design, setting and data sources}

We conducted a multinational cohort study using routinely-collected healthcare data from January to June 2020 from the US, Spain, and the United Kingdom (UK). All data were standardized to the Observational Medical Outcomes Partnership (OMOP) Common Data Model (CDM). ${ }^{15}$ The openscience Observational Health Data Sciences and Informatics (OHDSI) network maintains the OMOP-CDM, along with a wide range of tools developed by its members to facilitate analyses of mapped data. ${ }^{16}$ 
medRxiv preprint doi: https://doi.org/10.1101/2020.09.02.20185173; this version posted September 3, 2020. The copyright holder for this preprint (which was not certified by peer review) is the author/funder, who has granted medRxiv a license to display the preprint in

It is made available under a CC-BY-NC-ND 4.0 International license.

We included primary, outpatient and inpatient care data from electronic health records (EHRs) and health insurance claims data. Primary care data sources included the Clinical Practice Research Datalink (CPRD), with patients from over 600 general practices in the $\mathrm{UK} ;{ }^{17}$ and the Information System for Research in Primary Care (SIDIAP), covering approximately $80 \%$ of the population in Catalonia, Spain. ${ }^{18}$ Data from the US included: the Stanford Medicine Research Data Repository (STARR-OMOP), with data from Stanford Health Care, ${ }^{19}$ Columbia University Irving Medical Center (CUIMC), covering New York-Presbyterian Hospital and its affiliated physician practices; IQVIA Open Claims, which are pre-adjudicated claims collected from office based physicians and specialists covering over 300 million lives ( 80\% of the US population); and the United States Department of Veterans Affairs (VA-OMOP), covering the national Department of Veterans Affairs health care system which serves more than 9 million enrolled Veterans (of whom $93 \%$ are male). A more detailed description of the included data sources is available in Appendix 1.

\section{Study participants}

For our first objective (obese vs non-obese patients with COVID-19), we included two cohorts of patients: 1) all patients diagnosed with COVID-19 (clinical diagnosis and/or positive test for SARSCoV-2), and, 2) all patients hospitalized with a COVID-19 diagnosis. The codes used to identify a COVID-19 diagnosis are described in Appendix 2. We included individuals with at least one year of observation time prior to index date to capture observed baseline characteristics. In the diagnosed cohort, index date was defined as the date of COVID-19 clinical diagnosis or the earliest test day registered within seven days of a first positive test, whichever occurred first. In the hospitalized cohort, index date was the day of hospitalization. Patients were followed from the index date to the earliest of death, end of the observation period, ${ }^{20}$ or 30 days.

Patients hospitalized with COVID-19 were identified as those having a hospitalization episode along with a clinical diagnosis or positive SARS-CoV-2 test within a time window from 21 days prior to admission up to the end of their hospitalization. We chose this time window to include patients with a diagnosis prior to hospitalization and to allow for a record delay in test results or diagnoses.

Both the diagnosed and hospitalized COVID-19 cohorts were stratified by obesity (obese vs nonobese). Obesity was defined as having an ever-recorded obesity diagnosis (Appendix 3) and/or a body mass index (BMI) measurement between 30 and $60 \mathrm{~kg} / \mathrm{m}^{2}$ and/or a body weight measurement between 120 and 200 kilograms prior or at index date. Non-obese patients were those who did not fulfil the obesity definition. 
medRxiv preprint doi: https://doi.org/10.1101/2020.09.02.20185173; this version posted September 3, 2020. The copyright holder for this preprint (which was not certified by peer review) is the author/funder, who has granted medRxiv a license to display the preprint in

It is made available under a CC-BY-NC-ND 4.0 International license.

For our second objective (obese COVID-19 vs obese influenza patients), we reproduced these cohorts for patients with a clinical diagnosis and/or a positive test for influenza in the season 20172018 (Appendix 2).

\section{Baseline characteristics and outcomes of interest}

We obtained information on the participants' sex (female, male) and age at index date. Clinical epidemiologists generated a list of codes for the identification of prior medical conditions and outcomes of interest using a web-based integrated platform (ATLAS tool). ${ }^{20}$

We identified comorbidities from up to one year prior to index date. We selected conditions based on their prevalence in the cohorts of the participating sites, as well as on their clinical relevance to the obesity and the COVID-19 research field. ${ }^{4,21}$ Comorbidities were identified based on the Systematized Nomenclature of Medicine (SNOMED) hierarchy, with all descendant codes included. ${ }^{20}$ We created specific definitions for comorbidities of particular interest; the detailed definitions of these variables can be consulted in Appendix 3.

Our main 30-day outcomes of interest were hospitalization and death for the diagnosed cohorts, and requirement of intensive services (identified by a recorded mechanical ventilation and/or a tracheostomy and/or extracorporeal membrane oxygenation procedure) and death for the hospitalized cohorts. For the hospitalized cohort of COVID-19 patients, we also report respiratory, cardiovascular, thromboembolic, and other events occurring in the 30 days after the index date.

\section{Statistical analysis}

We describe the number of patients included and the prevalence of obesity in each database. We report the percentage of COVID-19 diagnoses that was identified by a positive SARS-CoV-2 test, as well as the socio-demographics, comorbidities, and outcomes as proportions (calculated by the number of persons within a given category, divided by the total number of persons) for each database, by obesity status.

A common analytical code was developed for the OHDSI Methods library which was run locally in each database (available at https://github.com/ohdsi-studies/Covid19CharacterizationCharybdis), and only aggregate results from each database were publicly-shared.

We used R version 3.6 for data visualization. All the data partners obtained Institutional Review Board (IRB) approval or exemption to conduct this study. 
medRxiv preprint doi: https://doi.org/10.1101/2020.09.02.20185173; this version posted September 3, 2020. The copyright holder for this preprint (which was not certified by peer review) is the author/funder, who has granted medRxiv a license to display the preprint in

It is made available under a CC-BY-NC-ND 4.0 International license .

\section{Results}

\section{Prevalence of obesity}

The COVID-19 dataset included 627044 diagnosed and 160013 hospitalized patients. The diagnosed cohort consisted of 502650 from the US (STARR-OMOP: 3328; CUIMC: 8519; IQVIA-OpenClaims: 466 191; VA-OMOP: 24 612), 122058 from Spain (SIDIAP), and 2336 patients from the UK (CPRD). The hospitalized cohort included 141816 patients from the US (STARR-OMOP: 615; CUIMC: 2600; IQVIA-OpenClaims: 133091 and VA-OMOP: 5510) and 18 197 from Spain (SIDIAP). Among diagnosed and hospitalized patients, 207859 (33\%) and 63866 (40\%) were obese, respectively. In all databases, the prevalence of obesity was lower among diagnosed patients than among those hospitalized, with differences ranging from 5\% (IQVIAOpenClaims) to $16 \%$ (SIDIAP) (Table 1).

The influenza dataset included 4549568 patients diagnosed and 239535 patients hospitalized with influenza. Among patients diagnosed or hospitalized with influenza, 688553 (15\%) and 67257 (28\%) were obese, respectively. Aside from VA-OMOP, obesity prevalence was lower among patients diagnosed or hospitalized with influenza compared to those with COVID-19, with differences ranging from 9\% (CPRD) to 18\% (IQVIA-OpenClaims) among diagnosed, and ranging from 5\% (VA-OMOP) to $11 \%$ (CUIMC) among hospitalized patients.

\section{Baseline socio-demographics}

Overall, diagnosed patients were mainly female and aged between 18 and 64 years (Table 1 and Supplementary table 3). However, the proportion of patients aged above 64 years was higher among obese patients with COVID-19 compared to non-obese for SIDIAP, STARR-OMOP, CUIMC, and VA-OMOP and slightly lower for CPRD and IQVIA-OpenClaims. The proportion of patients younger than 18 was very low for obese diagnosed COVID-19 patients, with less than $2 \%$ in all databases, whereas it was greater than $10 \%$ in four databases for obese influenza patients.

Aside from VA-OMOP, in the hospitalized cohorts, female sex was more common among obese COVID-19 (ranging from 51\% to 55\%) and influenza cases (from 55\% to 63\%) than in non-obese COVID-19 (from 40\% to 50\%) (Table 1). Overall, hospitalized patients were older than those diagnosed. In the hospitalized cohorts, obese patients with COVID-19 were fairly consistently younger than non-obese (except for SIDIAP) and obese influenza patients. The proportion of patients aged above 65 ranged from $36 \%$ to $63 \%$ for obese, from $43 \%$ to $73 \%$ for non-obese and from $54 \%$ to $72 \%$ for obese influenza patients. 
medRxiv preprint doi: https://doi.org/10.1101/2020.09.02.20185173; this version posted September 3, 2020. The copyright holder for this preprint (which was not certified by peer review) is the author/funder, who has granted medRxiv a license to display the preprint in

It is made available under a CC-BY-NC-ND 4.0 International license .

\section{Baseline comorbidities}

In the diagnosed cohorts, obese patients with COVID-19 consistently had a higher prevalence of comorbidities compared to non-obese patients (upper part of Figure 1.A and Supplementary table 4). For example, while the prevalence of hypertension for the obese ranged from $30 \%$ to $32 \%$ in Europe (CPRD and SIDIAP) and from 55\% to $81 \%$ in the US, in the non-obese it ranged from $12 \%$ to $16 \%$ and from 26 to $53 \%$, respectively. When compared to obese patients with influenza, obese patients with COVID-19 had a higher prevalence of comorbidities for SIDIAP, STARR-OMOP, and IQVIA-OpenClaims whereas they had fewer comorbidities for CPRD and CUIMC (Figure 1.B, Supplementary table 6).

As in the diagnosed cohort, hospitalized obese patients with COVID-19 had a higher prevalence of comorbidities than non-obese; however, the differences between groups were less obvious (lower part of Figure 1.A., Supplementary table 5). For example, heart disease differed by $20 \%$ among those diagnosed in VA-OMOP (obese: 60\%, non-obese: $40 \%$ ) and by $9 \%$ among those hospitalized (obese: $74 \%$, non-obese: $65 \%$ ). Contrary to the findings for the diagnosed cohort, hospitalized obese patients with influenza had a higher prevalence of comorbidities compared to COVID-19 patients (lower part of Figure 1.B., Supplementary table 6), except for mental health conditions which were higher in COVID-19 patients in some databases (anxiety in SIDIAP and VA-OMOP and dementia in IQVIA-OpenClaims and VA-OMOP).

\section{0-day outcomes of interest}

In the diagnosed cohorts, hospitalizations rates were higher among obese COVID-19 patients than among non-obese and obese influenza patients in all databases (Figure 2). For example, in IQVIAOpenClaims, the proportion of patients hospitalized was $32 \%$ and $26 \%$ for obese and non-obese patients with COVID-19 and 9\% for obese patients with influenza. Among obese COVID-19 patients, fatality ranged from 5\% to $12 \%$. While CPRD and VA-OMOP had similar fatality in obese and non-obese; in SIDIAP and CUIMC, obese patients had a higher fatality than non-obese (7\% vs $3 \%$ and $8 \%$ vs 5\%, respectively). Among obese COVID-19 patients, fatality was higher than among obese influenza patients (range: $0 \cdot 1 \%$ to $3 \%$ ).

In the hospitalized cohorts, obese patients with COVID-19 required intensive services more frequently than non-obese in STARR-OMOP (obese: 9\% vs non-obese: 6\%), IQVIA-OpenClaims (13\% vs 10\%) and VA-OMOP (22\% vs $15 \%)$. Percentages in CUIMC were too small to assess differences ( $2.3 \%$ vs $2 \cdot 0 \%$ ). Hospitalized obese patients with COVID-19 also required intensive services more often than obese patients with influenza in IQVIA-OpenClaims (13\% vs 3\%) and VA-OMOP (22\% vs 6\%) whereas in CUIMC (2\% vs 6\%) the opposite was observed. 
medRxiv preprint doi: https://doi.org/10.1101/2020.09.02.20185173; this version posted September 3, 2020. The copyright holder for this preprint (which was not certified by peer review) is the author/funder, who has granted medRxiv a license to display the preprint in

It is made available under a CC-BY-NC-ND 4.0 International license .

There were no notable differences in fatality between obese and non-obese hospitalized patients with COVID-19: $14 \%$ vs $11 \%$ in SIDIAP, $20 \%$ vs $21 \%$ in CUIMC and $16 \%$ vs $18 \%$ in VA-OMOP. However, fatality among obese COVID-19 cases was much higher than among obese influenza patients (2\% in CUIMC and $4 \%$ in VA-OMOP).

Overall, obese patients with COVID-19 had adverse events occurring in the 30 days after the index date more frequently than non-obese (Table 2). This was especially evident for the most frequent events, namely acute respiratory distress syndrome (ARDS) (range: $15 \%$ to $46 \%$ among obese, range: $10 \%$ to $41 \%$ among non-obese) and heart failure (7\% to $23 \%$ among obese, $3 \%$ to $17 \%$ among non-obese) during hospitalization. Sepsis, cardiac arrhythmia, and total cardiovascular disease events were also slightly more frequent among obese COVID-19 patients compared to nonobese. Acute kidney injury was the only outcome that was more frequent among non-obese; however, except for CUIMC, differences were small. For the rest of the reported events, numbers were too small to assess differences between obese and non-obese COVID-19 patients.

\section{Discussion}

In this large cohort including 627044 COVID-19 and 4549568 influenza patients from the US, Spain, and the UK, we found that the prevalence of obesity was higher among COVID-19 patients hospitalized compared to those diagnosed and was higher in both COVID-19 cohorts compared to the influenza cohorts. Obese patients diagnosed and hospitalized with COVID-19 were more commonly female, and presented with more comorbidities and adverse outcomes than non-obese patients. Although obese COVID-19 patients were younger and less likely to have comorbidities than obese influenza patients in the hospitalized cohorts, they more frequently had adverse outcomes.

Given the prevalence of obesity in the US (37\%), the UK (27\%) and Spain (24\%), a high proportion of obese patients among COVID-19 cases was expected. ${ }^{22}$ However, the prevalence of obesity among COVID-19 patients was higher than the general population in the three countries, which is suggestive of an increased risk of diagnosis in obese patients. Obese individuals could be more likely to seek care and be tested for SARS-CoV-2 since they are a high-risk, multimorbid population and could be more prone to respiratory symptoms due to their compromised pulmonary function. Alternatively, they might have an increased risk of COVID-19 infection that could be explained through differences in exposure and/or vulnerability. Two studies from Spain and the UK found a higher risk of being diagnosed with COVID-19 in obese individuals. ${ }^{7,23}$ We also found a 
medRxiv preprint doi: https://doi.org/10.1101/2020.09.02.20185173; this version posted September 3, 2020. The copyright holder for this preprint (which was not certified by peer review) is the author/funder, who has granted medRxiv a license to display the preprint in

It is made available under a CC-BY-NC-ND 4.0 International license .

higher proportion of obesity among hospitalized COVID-19 patients compared to those diagnosed. The prevalence of obesity from this study was similar to three cohort studies from the US that reported $40 \%, 42 \%$ and $48 \%$ of hospitalized patients were obese. ${ }^{9-11}$ These findings could reflect a preferential care in high-risk populations but also an increased risk of severe disease among obese patients.

Prior characterization studies from the hospital setting have consistently reported that COVID-19 hospitalized patients are more frequently male. ${ }^{10,11}$ We found, however, that women predominate among hospitalized obese patients. Since the prevalence of obesity is similar for men and women in the three countries, our findings could reflect that obesity is a greater risk factor for hospitalization among women compared to men. ${ }^{22}$ Some of the biological hypotheses that have been posited to explain the greater risk of poor COVID-19 outcomes among men are similar to those proposed for obese individuals. For example, one hypothesis argues that sex differences in the immune response increase men's vulnerability. Men have higher levels of interleukin-6 and tumour necrosis factor alpha, which are the main drivers of the phenomenon of "cytokine storm" that has been observed in severe COVID-19 patients. ${ }^{24,25}$ Obese individuals also have higher levels of these pro-inflammatory cytokines. ${ }^{26}$ Similarly, men have higher levels of angiotensin-converting enzyme 2 , which are also elevated in obese individuals. ${ }^{25,27}$

We also found that compared to non-obese, patients with obesity were older among those diagnosed with COVID-19 and younger in those hospitalized. The former observation might be explained by the early identification of both older age and obesity as risk factors for COVID-19. ${ }^{4}$ This could have increased the frequency of testing among people with these characteristics. Conversely, the differences observed in the hospital setting could be related to a greater risk of severe outcomes among individuals with obesity younger than $60 .{ }^{28}$ Although younger individuals have less risk of infections and complications than older people due to having fewer comorbidities and a stronger immune system, ${ }^{29,30}$ this is not the case for obese individuals. ${ }^{31,32}$ Therefore, the more fragile health of obese patients even in the young may contribute to the observed age pattern for the individuals hospitalized with obesity.

Obese individuals differed also in terms of comorbidities. Unsurprisingly, the highest differences were observed in obesity-related conditions, such as hypertension, diabetes, and heart disease, which have been identified as risk factors for severe COVID-19 outcomes. ${ }^{7,8,10,13}$ The selected comorbidities likely represent only a small proportion of the differences that should be considered when assessing the links between obesity and COVID-19. For instance, obesity is strongly interlinked with socioeconomic status and ethnicity, and disproportionately affects disadvantaged populations. ${ }^{29}$ In the US, the prevalence of obesity is higher among Hispanic and African Americans than among their White counterparts. These disparities have been hypothesized as a contributing factor explaining ethnic differences in the proportion of hospitalizations. ${ }^{33}$ Given the links between obesity and the social determinants of health, obese individuals might be more at risk 
medRxiv preprint doi: https://doi.org/10.1101/2020.09.02.20185173; this version posted September 3, 2020. The copyright holder for this preprint (which was not certified by peer review) is the author/funder, who has granted medRxiv a license to display the preprint in

It is made available under a CC-BY-NC-ND 4.0 International license .

of COVID-19 infection and complications due to more precarious working conditions and barriers in healthcare access. Unfortunately, due to data unavailability, we could not directly explore socioeconomic status or ethnicity differences in our study.

Finally, obese individuals experienced more frequently adverse events than non-obese, including hospitalization and requirement of intensive services. These results, however, must be interpreted carefully considering the differences in socio-demographics and comorbidities between obese and non-obese individuals. Despite this limitation, our results are in line with previous studies where obesity was associated with an increased risk of hospitalization and mortality, adjusting for sex, age, and comorbidities. ${ }^{7,810,13}$ Given the scarcity of evidence regarding the frequency of specific adverse events during hospitalization among obese patients, our findings are of special interest to the field and should be addressed in upcoming associative studies.

Since obesity has been associated with different forms of influenza, an association with COVID-19 was expected from the beginning of the pandemic. ${ }^{34}$ Interestingly, we found that the prevalence of obesity was higher among both COVID-19 diagnosed and hospitalized patients compared to those with seasonal influenza, which may be suggestive of an inherent vulnerability towards COVID-19 among obese patients. In both COVID-19 and influenza cohorts, female sex was more frequent than male sex. A large study comparing hospitalized patients with COVID-19 to those with influenza found that COVID-19 patients were predominantly male whereas those with influenza were mostly women. ${ }^{35}$ While our study replicated those findings for non-obese patients, we observed that women predominated among obese patients hospitalized with COVID-19. Thus, our results provide a finer picture of the most frequent sex of patients with COVID-19 among those with obesity. Older age has been associated with an increased risk of more severe forms of both COVID-19 and influenza, ${ }^{3}$ however, we observed obese patients with COVID-19 were younger than those with influenza. Our findings are in line with previous studies that reported younger ages among individuals with H1N1 and COVID-19 compared to seasonal influenza (obese and non-obese individuals together). ${ }^{35,36}$ Finally, although obese patients diagnosed with COVID-19 had more comorbidities than obese influenza patients the opposite was observed among hospitalized patients. This could reflect either a higher virulence of SARS-CoV-2 compared to influenza or a differential pattern in clinical practice, with a lower threshold for hospitalization in COVID-19 cases. However, obese patients with COVID-19 consistently had worse outcomes than influenza patients. These results put in to question the justification that worse outcomes among obese patients with COVID19 are merely due to a higher prevalence of co-existing conditions. ${ }^{37}$

Our study has several strengths, such as its large amount of data. This study contains information on 627044 COVID-19 cases from six databases of three different countries and provides a wide 
medRxiv preprint doi: https://doi.org/10.1101/2020.09.02.20185173; this version posted September 3, 2020. The copyright holder for this preprint (which was not certified by peer review) is the author/funder, who has granted medRxiv a license to display the preprint in

It is made available under a CC-BY-NC-ND 4.0 International license .

overview of the characteristics and outcomes of patients with and without obesity. Almost 29000 unique aggregate characteristics were generated and made publicly available. This was accomplished through the coordinated efforts of the OHDSI community to provide a rapid response to the COVID-19 pandemic. We employed a federated analysis approach that allowed us to respect the confidentiality of patient records at all times, and we emphasized transparency throughout the study, making methods, tools, and results publicly available.

Our study also has limitations. One limitation is its descriptive nature. Since we aimed to characterize and compare patients with and without obesity, statistical tests and modelling were out of scope in the developed analytical packages. However, our findings were consistent across databases. In addition, the exhaustive characterization performed in this study supports the generation of new hypotheses that can be tested in detail in future studies. Second, we cannot exclude a selection bias of COVID-19 cases due to underreporting in the context of testing restrictions and asymptomatic or paucisymptomatic cases that usually do not seek medical care.

Additionally, testing policies have varied across countries and time depending on the course of the pandemic. The inclusion of COVID-19 cases clinically diagnosed (without being tested) in different countries and settings likely provided consistency to our data, although it might have incurred in false positives. Third, we did not have information on BMI as a continuous variable, which prevented us from investigating the impact of different categories of obesity in COVID-19 outcomes. This might explain the higher proportion of comorbidities and outcomes observed in the US databases, as obese individuals from the US might be more obese than those from Europe. Fourthly, we cannot discard that the differences found in the COVID-19/seasonal influenza comparison may have been influenced by temporal changes in clinical practice standards and coding. Further, the use of influenza vaccination among high-risk population groups likely contributed to the observed low proportion of adverse events among influenza patients. ${ }^{38}$ Finally, this study was underpinned by routinely-collected data which can raise concerns about the quality of the data. Some databases are prone to oversampling certain groups of people as a result of how these data are captured (e.g. the Veterans Affairs system historically serves more men than women, routine claims data may only reflect health outcomes in commercially insured populations, etc). Obesity, comorbidities, and outcomes were assessed based on having a record of a condition/measurement, therefore they may be underestimated. Even still, the consistency of our findings across several databases that differ by setting and country lends credence to the generalizability of our findings.

In this large international cohort, we showed that obese patients with COVID-19 were more likely to be female, had more comorbidities and worse outcomes than non-obese patients. We provide novel evidence that the prevalence of obesity is higher among COVID-19 patients compared to those with seasonal influenza and that obese hospitalized COVID-19 patients have worse outcomes 
medRxiv preprint doi: https://doi.org/10.1101/2020.09.02.20185173; this version posted September 3, 2020. The copyright holder for this preprint (which was not certified by peer review) is the author/funder, who has granted medRxiv a license to display the preprint in

It is made available under a CC-BY-NC-ND 4.0 International license .

than obese patients with influenza, despite presenting with fewer comorbidities. Our results may be useful in guiding clinical practice and aid future preventative strategies for obese individuals, as well as providing useful data to support subsequent association studies focussed on obesity and COVID-19.

\section{Ethical approval}

All the data partners received Institutional Review Board (IRB) approval or exemption. STARROMOP had approval from IRB Panel \#8 (RB-53248) registered to Leland Stanford Junior University under the Stanford Human Research Protection Program (HRPP). The use of VA data was reviewed by the Department of Veterans Affairs Central IRB, was determined to meet the criteria for exemption under Exemption Category 4(3), and approved for Waiver of HIPAA Authorization. The research was approved by the Columbia University Institutional Review Board as an OHDSI network study. The use of SIDIAP was approved by the Clinical Research Ethics Committee of the IDIAPJGol (project code: 20/070-PCV). The use of CPRD was approved by the Independent Scientific Advisory Committee (ISAC) (protocol number 20_059RA2). The use of IQVIA-OpenClaims was exempted from IRB approval.

\section{Competing interest statement}

All authors have completed the ICMJE uniform disclosure form at www.icmje.org/coi_disclosure.pdf and declare: Mr. Sena reports personal fees from Janssen Research \& Development, outside the submitted work; Dr. DuVall reports grants from Anolinx, LLC, grants from Astellas Pharma, Inc, grants from AstraZeneca Pharmaceuticals LP, grants from Boehringer Ingelheim International $\mathrm{GmbH}$, grants from Celgene Corporation, grants from Eli Lilly and Company, grants from Genentech Inc., grants from Genomic Health, Inc., grants from Gilead Sciences Inc., grants from GlaxoSmithKline PLC, grants from Innocrin Pharmaceuticals Inc., grants from Janssen Pharmaceuticals, Inc., grants from Kantar Health, grants from Myriad Genetic Laboratories, Inc., grants from Novartis International AG, grants from Parexel International Corporation through the University of Utah or Western Institute for Biomedical Research, outside the submitted work; Mr Ahmed reports funding from the NIHR Oxford Biomedical Research Centre (BRC), Aziz Foundation, Wolfson Foundation, and the Royal College Surgeons of England; Dr. Golozar reports personal fees from Regeneron Pharmaceuticals, outside the submitted work. She is a full-time employee at Regeneron Pharmaceuticals. This work was not conducted at Regeneron Pharmaceuticals. Miss Lane is supported by a Medical Research Council Doctoral 
medRxiv preprint doi: https://doi.org/10.1101/2020.09.02.20185173; this version posted September 3, 2020. The copyright holder for this preprint (which was not certified by peer review) is the author/funder, who has granted medRxiv a license to display the preprint in

It is made available under a CC-BY-NC-ND 4.0 International license .

Research Fellowship (MR/K501256/1) and a Versus Arthritis Clinical Research Fellowship (21605). Dr. Morales is supported by a Wellcome Trust Clinical Research Development Fellowship (Grant 214588/Z/18/Z) and reports grants from Chief Scientist Office (CSO), grants from Health Data Research UK (HDR-UK), grants from National Institute of Health Research (NIHR), outside the submitted work; Dr. Nyberg reports other from AstraZeneca, outside the submitted work; Dr. Subbian reports grants from National Science Foundation, grants from State of Arizona; Arizona Board of Regents, grants from Agency for Healthcare Research and Quality, outside the submitted work; Dr Prieto-Alhambra reports grants and other from AMGEN; grants, non-financial support and other from UCB Biopharma; grants from Les Laboratoires Servier, outside the submitted work; and Janssen, on behalf of IMI-funded EHDEN and EMIF consortiums, and Synapse Management Partners have supported training programs organized by DPA's department and open for external participants. Ms. Kostka and Dr. Reich report being employees of IQVIA Inc. Dr. Ryan is an employee of Janssen Research and Development and shareholder of Johnson \& Johnson. The views expressed are those of the authors and do not necessarily represent the views or policy of the Department of Veterans Affairs or the United States Government. No other relationships or activities that could appear to have influenced the submitted work.

\section{Transparency declaration}

Lead authors affirm that the manuscript is an honest, accurate, and transparent account of the study being reported; that no important aspects of the study have been omitted; and that any discrepancies from the study as planned have been explained.

\section{Contributorship statement}

MR, ER, APU, PR, DPA, KK and TDS conceived and designed the study. SLD, TF, KEL, MEM, $\mathrm{KN}, \mathrm{JDP}, \mathrm{CGR}, \mathrm{NHS}, \mathrm{PR}, \mathrm{KK}$ and TDS coordinated data contributions at their respective sites. AP, AGS, TF, SFB, JDP, KK and TDS analyzed the data; MR, ER and AP produced the figures and tables. MR, ER, EB, DRM, FN, PR, LMS, DPA, KK and TDS interpreted the data. MR, ER and TDS searched the literature and wrote the first draft with insightful contributions from EB, LYHL, JCEL, DRM, FN, PR, LMS, DPA and KK. All authors contributed to the revision of the first draft, reviewed and approved the final version of the manuscript.

\section{Acknowledgements}

We would like to acknowledge the patients who suffered from or died of this devastating disease, and their families and carers. We would also like to thank the healthcare professionals involved in 
medRxiv preprint doi: https://doi.org/10.1101/2020.09.02.20185173; this version posted September 3, 2020. The copyright holder for this preprint (which was not certified by peer review) is the author/funder, who has granted medRxiv a license to display the preprint in It is made available under a CC-BY-NC-ND 4.0 International license .

the management of COVID-19 during these challenging times, from primary care to intensive care units.

\section{Data sharing statement}

Analyses were performed locally in compliance with all applicable data privacy laws. Although the underlying data is not readily available to be shared, authors contributing to this paper have direct access to the data sources used in this study. All results (e.g. aggregate statistics, not presented at a patient-level with redactions for minimum cell count) are available for public inquiry. These results are inclusive of site-identifiers by contributing data sources to enable interrogation of each contributing site. All analytic code and result sets are made available at: https://github.com/ohdsistudies/Covid19CharacterizationCharybdis 
Table 1: Sociodemographic characteristics of obese and non-obese patients diagnosed and hospitalized with COVID-19 and influenza in the season $2017-2018$

\begin{tabular}{|c|c|c|c|c|c|c|c|c|c|c|c|c|}
\hline & \multicolumn{2}{|c|}{ CPRD } & \multicolumn{2}{|c|}{ SIDIAP } & \multicolumn{2}{|c|}{ STARR-OMOP } & \multicolumn{2}{|c|}{ CUIMC } & \multicolumn{2}{|c|}{$\begin{array}{c}\text { IQVIA- } \\
\text { OpenClaims }\end{array}$} & \multicolumn{2}{|c|}{ VA-OMOP } \\
\hline & Obese & $\begin{array}{r}\text { Non- } \\
\text { obese }\end{array}$ & Obese & $\begin{array}{c}\text { Non- } \\
\text { obese }\end{array}$ & Obese & $\begin{array}{c}\text { Non- } \\
\text { obese }\end{array}$ & Obese & $\begin{array}{r}\text { Non- } \\
\text { obese }\end{array}$ & Obese & $\begin{array}{l}\text { Non- } \\
\text { obese }\end{array}$ & Obese & $\begin{array}{l}\text { Non- } \\
\text { obese }\end{array}$ \\
\hline $\begin{array}{l}\text { Diagnosed with COVID-19, } \\
\text { n (\%)* }\end{array}$ & $\begin{array}{r}976 \\
(41 \cdot 8)\end{array}$ & $\begin{array}{r}1360 \\
(58 \cdot 2)\end{array}$ & $\begin{array}{r}36409 \\
(29 \cdot 8)\end{array}$ & $\begin{array}{r}85649 \\
(70 \cdot 2)\end{array}$ & $\begin{array}{r}1157 \\
(34 \cdot 8)\end{array}$ & $\begin{array}{r}2171 \\
(65 \cdot 2)\end{array}$ & $\begin{array}{r}3446 \\
(40 \cdot 5)\end{array}$ & $\begin{array}{r}5073 \\
(59 \cdot 5)\end{array}$ & $\begin{array}{c}154325 \\
(33 \cdot 1)\end{array}$ & $\begin{array}{c}311866 \\
(66 \cdot 9)\end{array}$ & $\begin{array}{l}11546 \\
(46 \cdot 9)\end{array}$ & $\begin{array}{r}13066 \\
(53 \cdot 1)\end{array}$ \\
\hline SARS-CoV-2 positive tests, $\%$ & $51 \cdot 5$ & $50 \cdot 3$ & $39 \cdot 2$ & $27 \cdot 2$ & $24 \cdot 4$ & $28 \cdot 6$ & $66 \cdot 7$ & $65 \cdot 5$ & $100 \cdot 0$ & $100 \cdot 0$ & $100 \cdot 0$ & $100 \cdot 0$ \\
\hline $\begin{array}{l}\text { Female sex, } \% \\
\text { Age, } \%\end{array}$ & $56 \cdot 2$ & $57 \cdot 2$ & $62 \cdot 5$ & $55 \cdot 9$ & $52 \cdot 9$ & $52 \cdot 8$ & $60 \cdot 9$ & $56 \cdot 4$ & $61 \cdot 0$ & $51 \cdot 7$ & $13 \cdot 2$ & $19 \cdot 0$ \\
\hline$<18$ years & $0 \cdot 0$ & $0 \cdot 0$ & $1 \cdot 2$ & $4 \cdot 7$ & $0 \cdot 0$ & $0 \cdot 0$ & $1 \cdot 2$ & $3 \cdot 5$ & $1 \cdot 0$ & $3 \cdot 9$ & & \\
\hline 18 to 64 years & $55 \cdot 4$ & $52 \cdot 3$ & $58 \cdot 9$ & $75 \cdot 6$ & $66 \cdot 2$ & $69 \cdot 6$ & $65 \cdot 2$ & $65 \cdot 8$ & $66 \cdot 7$ & $58 \cdot 0$ & $53 \cdot 7$ & $58 \cdot 4$ \\
\hline$>65$ years & $44 \cdot 7$ & $47 \cdot 7$ & $40 \cdot 0$ & $19 \cdot 6$ & $33 \cdot 8$ & $30 \cdot 4$ & $33 \cdot 6$ & $30 \cdot 6$ & $32 \cdot 3$ & $38 \cdot 2$ & $46 \cdot 3$ & $41 \cdot 6$ \\
\hline Hospitalized with COVID-19, n (\%)* & - & - & $\begin{array}{r}8403 \\
(46 \cdot 2)\end{array}$ & $\begin{array}{r}9794 \\
(53 \cdot 8)\end{array}$ & $\begin{array}{r}274 \\
(44 \cdot 6)\end{array}$ & $\begin{array}{r}341 \\
(55 \cdot 4)\end{array}$ & $\begin{array}{r}1408 \\
(54 \cdot 2)\end{array}$ & $\begin{array}{r}1192 \\
(45 \cdot 2)\end{array}$ & $\begin{array}{c}50863 \\
(38 \cdot 2)\end{array}$ & $\begin{array}{l}82228 \\
(61 \cdot 8)\end{array}$ & $\begin{array}{c}2918 \\
(53 \cdot 0)\end{array}$ & $\begin{array}{c}2592 \\
(47 \cdot 0)\end{array}$ \\
\hline SARS-CoV-2 positive tests, $\%$ & - & - & $76 \cdot 0$ & $72 \cdot 9$ & $10 \cdot 6$ & $18 \cdot 3$ & $88 \cdot 5$ & $91 \cdot 6$ & 100 & 100 & 100 & 100 \\
\hline $\begin{array}{l}\text { Female sex, } \% \\
\text { Age, } \%\end{array}$ & - & - & $51 \cdot 2$ & 39.9 & $51 \cdot 5$ & $49 \cdot 0$ & $54 \cdot 7$ & $39 \cdot 8$ & $55 \cdot 0$ & $43 \cdot 5$ & $6 \cdot 6$ & $4 \cdot 4$ \\
\hline$<18$ years & - & - & $0 \cdot 0$ & $0 \cdot 0$ & $0 \cdot 0$ & $0 \cdot 0$ & $0 \cdot 00$ & $0 \cdot 0$ & $0 \cdot 5$ & $2 \cdot 0$ & $0 \cdot 0$ & $0 \cdot 0$ \\
\hline 18 to 64 years & - & - & $37 \cdot 9$ & $50 \cdot 6$ & $64 \cdot 2$ & $57 \cdot 2$ & $53 \cdot 3$ & $34 \cdot 5$ & $51 \cdot 7$ & $38 \cdot 5$ & $37 \cdot 1$ & $27 \cdot 4$ \\
\hline$>65$ years & - & - & $62 \cdot 1$ & $49 \cdot 4$ & $35 \cdot 8$ & $42 \cdot 8$ & $46 \cdot 7$ & $65 \cdot 6$ & $47 \cdot 8$ & $59 \cdot 5$ & $62 \cdot 9$ & $72 \cdot 6$ \\
\hline $\begin{array}{l}\text { Diagnosed with Influenza, } \\
\text { n }(\%)^{*}\end{array}$ & $\begin{array}{r}835 \\
(32 \cdot 8)\end{array}$ & $\begin{array}{r}1708 \\
(67 \cdot 2)\end{array}$ & $\begin{array}{r}21984 \\
(19 \cdot 1)\end{array}$ & $\begin{array}{r}93240 \\
(80 \cdot 9)\end{array}$ & $\begin{array}{r}884 \\
(18 \cdot 3)\end{array}$ & $\begin{array}{r}3941 \\
(81 \cdot 7)\end{array}$ & $\begin{array}{r}1194 \\
(27 \cdot 6)\end{array}$ & $\begin{array}{r}3134 \\
(72 \cdot 4)\end{array}$ & $\begin{array}{c}645264 \\
(14 \cdot 7)\end{array}$ & $\begin{array}{c}3738 \\
349 \\
(85 \cdot 3)\end{array}$ & $\begin{array}{l}18392 \\
(47 \cdot 1)\end{array}$ & $\begin{array}{l}20643 \\
(52 \cdot 9)\end{array}$ \\
\hline $\begin{array}{l}\text { Female sex, } \% \\
\text { Age, } \%\end{array}$ & $57 \cdot 2$ & $54 \cdot 7$ & $59 \cdot 5$ & $51 \cdot 7$ & $61 \cdot 1$ & 51 & $65 \cdot 7$ & $54 \cdot 3$ & $64 \cdot 5$ & $53 \cdot 5$ & $13 \cdot 6$ & $11 \cdot 6$ \\
\hline$<18$ years & $0 \cdot 0$ & $11 \cdot 6$ & $10 \cdot 2$ & $26 \cdot 5$ & $10 \cdot 5$ & $59 \cdot 4$ & $13 \cdot 2$ & $47 \cdot 5$ & $12 \cdot 2$ & $48 \cdot 0$ & $0 \cdot 0$ & $0 \cdot 0$ \\
\hline
\end{tabular}




\begin{tabular}{|c|c|c|c|c|c|c|c|c|c|c|c|c|}
\hline 18 to 64 years & $51 \cdot 0$ & $53 \cdot 7$ & $68 \cdot 2$ & $66 \cdot 6$ & $63 \cdot 1$ & $29 \cdot 6$ & $53 \cdot 3$ & $33 \cdot 4$ & $66 \cdot 9$ & $39 \cdot 9$ & $52 \cdot 7$ & $54 \cdot 7$ \\
\hline$>65$ years & $49 \cdot 0$ & $34 \cdot 7$ & $21 \cdot 7$ & $6 \cdot 9$ & $26 \cdot 5$ & $11 \cdot 0$ & $33 \cdot 5$ & $19 \cdot 1$ & $20 \cdot 9$ & $12 \cdot 1$ & $47 \cdot 3$ & $45 \cdot 3$ \\
\hline $\begin{array}{l}\text { Hospitalized with Influenza, } \\
\text { n }(\%)^{*}\end{array}$ & - & & - & -1 & - & & $\begin{array}{r}290 \\
(44 \cdot 3)\end{array}$ & $\begin{array}{r}365 \\
(55 \cdot 7)\end{array}$ & $\begin{array}{l}62494 \\
(27 \cdot 2)\end{array}$ & $\begin{array}{c}167050 \\
(72 \cdot 8)\end{array}$ & $\begin{array}{l}4473 \\
(47 \cdot 9)\end{array}$ & $\begin{array}{l}4863 \\
(52 \cdot 1)\end{array}$ \\
\hline Female sex, $\%$ & - & - & - & - & - & - & $54 \cdot 7$ & $52 \cdot 3$ & $63 \cdot 0$ & $53 \cdot 9$ & $6 \cdot 6$ & $4 \cdot 4$ \\
\hline \multicolumn{13}{|l|}{ Age, $\%$} \\
\hline$<18$ years & - & - & - & - & - & - & $0 \cdot 0$ & $0 \cdot 0$ & $1 \cdot 8$ & $9 \cdot 6$ & $0 \cdot 0$ & $0 \cdot 0$ \\
\hline 18 to 64 years & - & - & - & - & - & - & 44.9 & $55 \cdot 9$ & $44 \cdot 4$ & $29 \cdot 3$ & $28 \cdot 0$ & $25 \cdot 3$ \\
\hline$>65$ years & - & - & - & - & - & - & $55 \cdot 1$ & $44 \cdot 2$ & $53 \cdot 9$ & $61 \cdot 1$ & $72 \cdot 0$ & $74 \cdot 7$ \\
\hline
\end{tabular}

Notes: * Proportion of obese and non-obese patients among all patients (row percentage); - data not available or below the minimum cell count required (5 individuals) Abbreviations: COVID-19: Coronavirus Disease 2019; CPRD: Clinical Practice Research Datalink; CUIMC: Columbia University Irving Medical Center; SIDIAP: Information System for Research in Primary Care; STARR-OMOP: Stanford Medicine Research Data Repository; VA-OMOP: United States Department of Veterans Affairs. 


\section{Figure 1: Previous comorbidities: a comparison between obese and non-obese patients with COVID-19 and obese influenza patients.}

\section{A. Obese and non-obese COVID-19 patients}

Prevalence of comorbidities for obese (red) and non-obese (blue) patients are depicted in overlapped horizontal bars. Grey colour is the overlap between groups (therefore, it shows the lowest value). For example, in CPRD, 32\% of obese and 16\% of non-obese patients have hypertension.
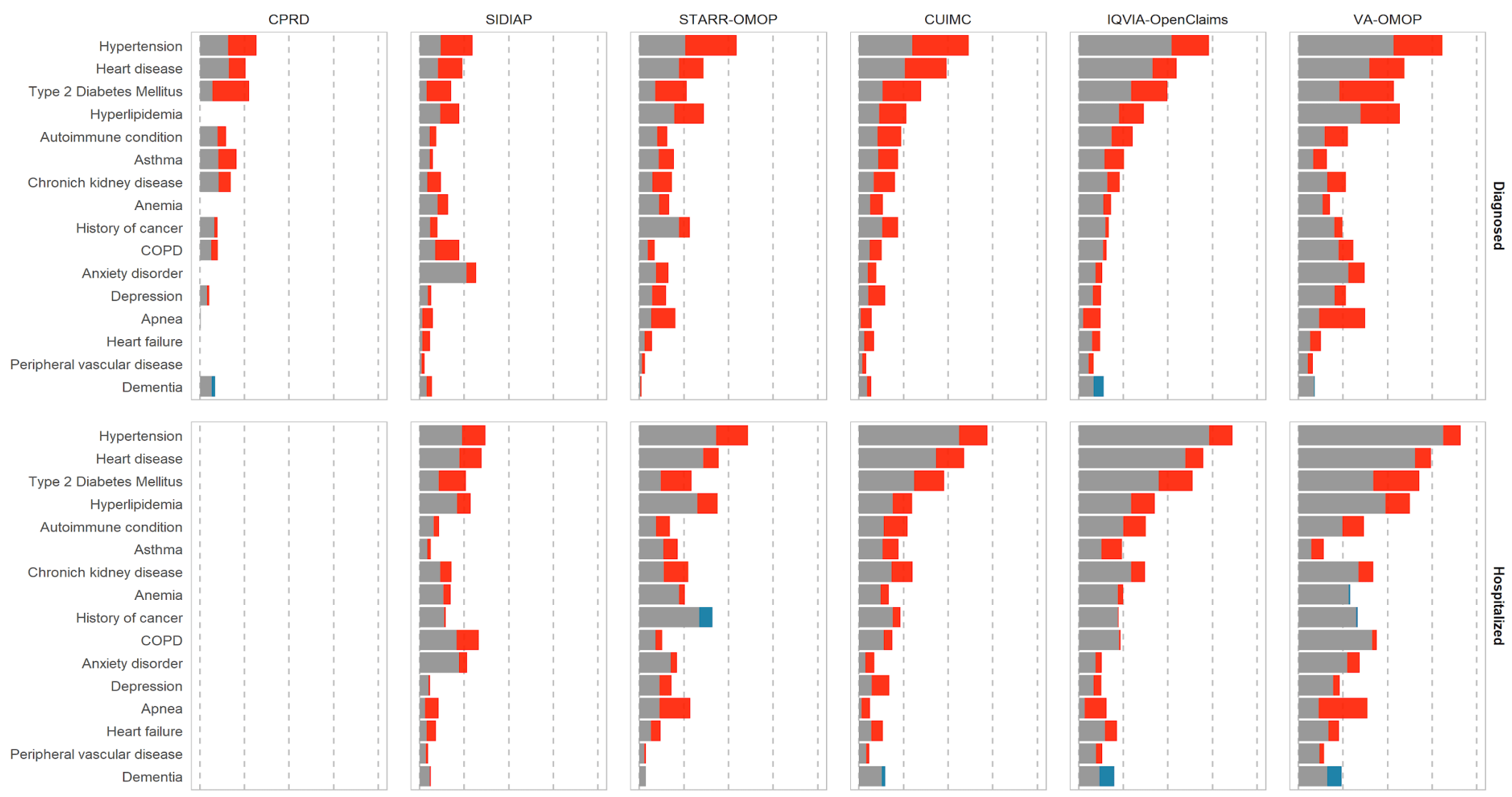

Overlap Obese COVID-19 Non-obese COVID-19 


\section{B. Obese patients with COVID-19 or with Influenza}

Prevalence of comorbidities for obese COVID-19 (red) and obese Influenza (green) patients are depicted in overlapped horizontal bars. Grey colour is the overlap between groups (lowest value).
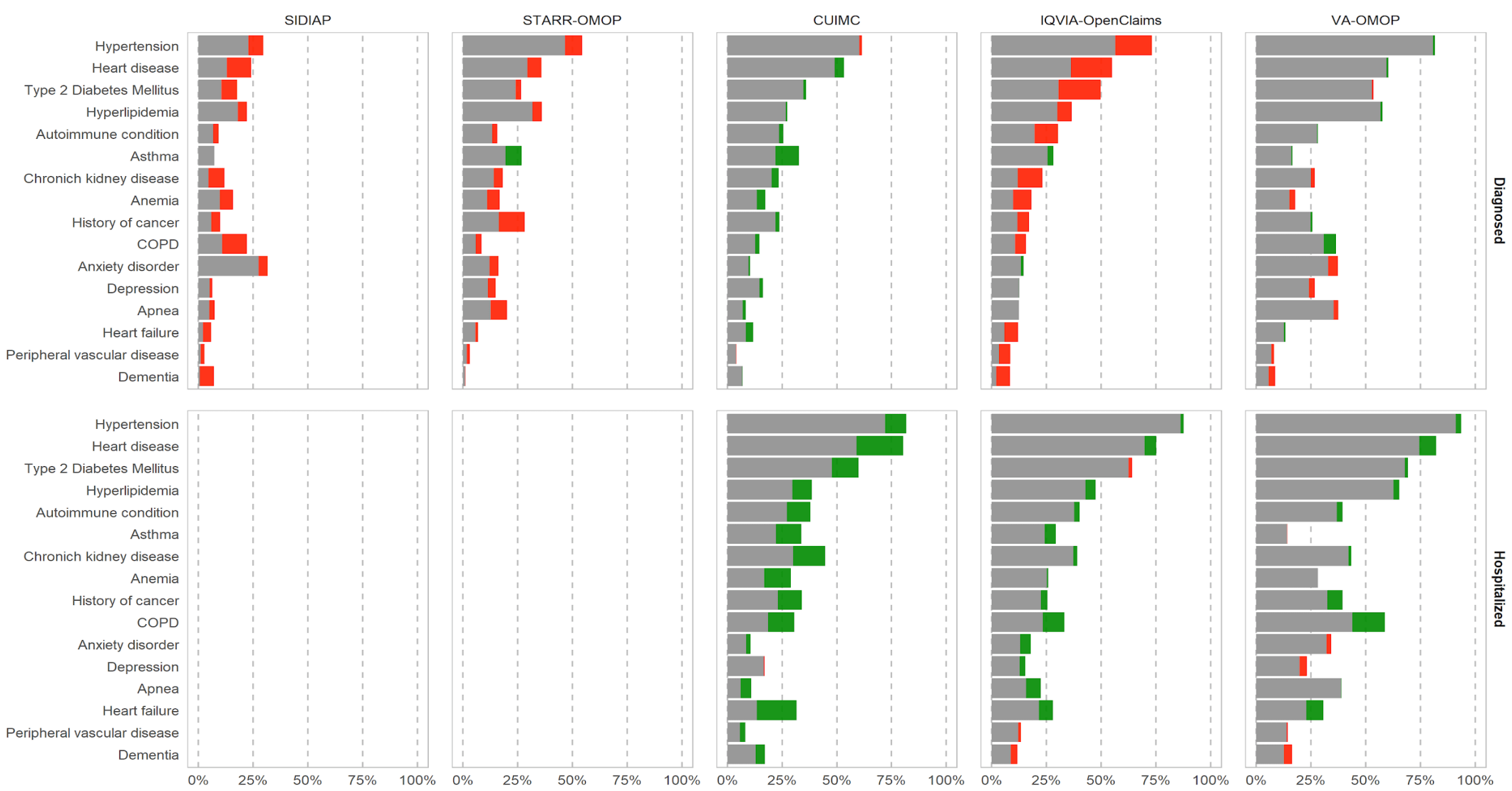

Overlap Obese COVID-19 Obese influenza

Abbreviations: COPD: Chronic obstructive pulmonary disease; COVID-19: Coronavirus Disease 2019; CPRD: Clinical Practice Research Datalink; CUIMC: Columbia University Irving Medical Center; SIDIAP: Information System for Research in Primary Care; STARR-OMOP: Stanford Medicine Research Data Repository; VA-OMOP: United States Department of Veterans Affairs. 
Figure 2: Main outcomes: a comparison between obese and non-obese patients with COVID-19 and obese influenza patients.

A. Obese and non-obese COVID-19 patients
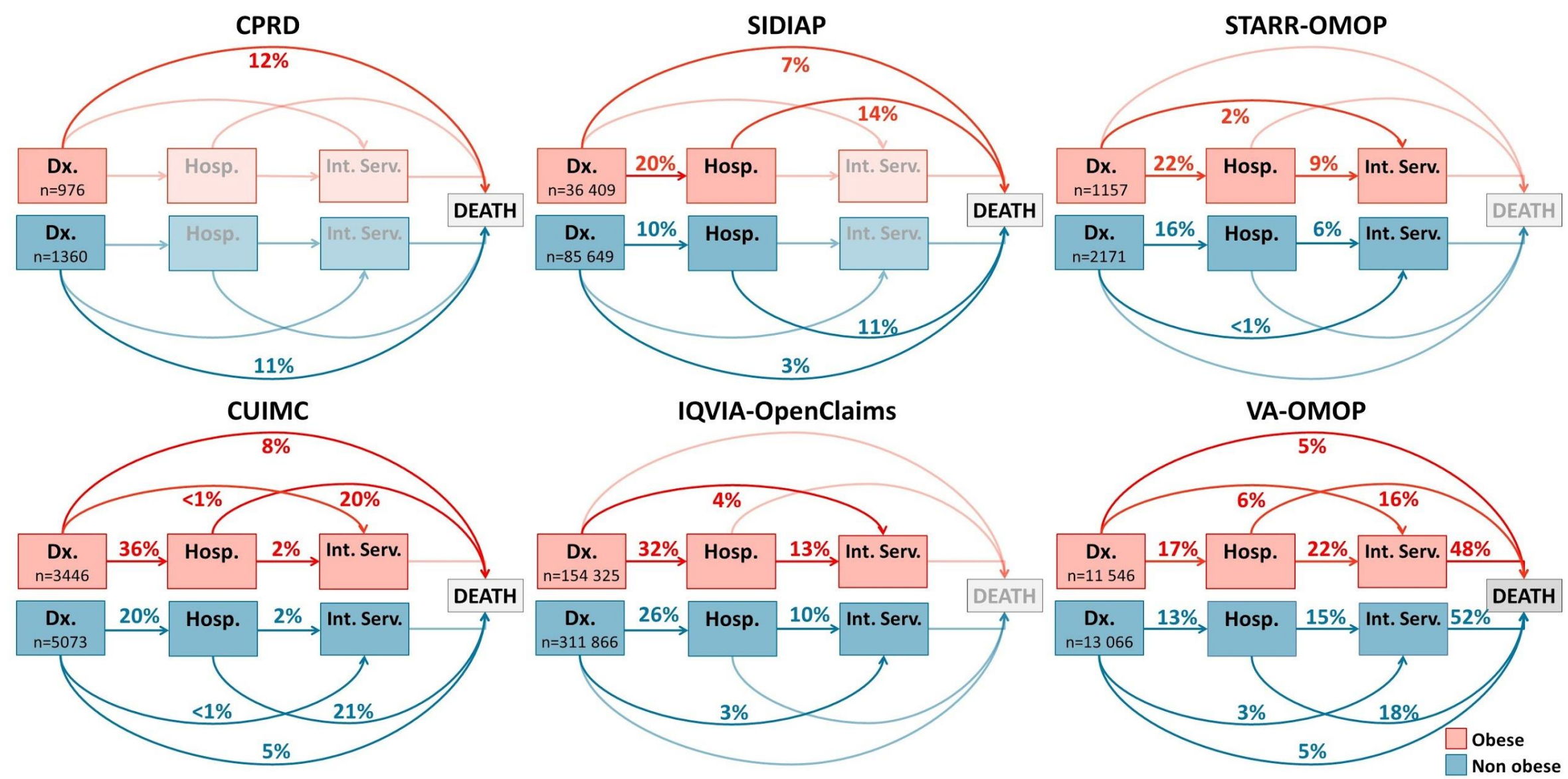
B. Obese COVID-19 and obese influenza patients
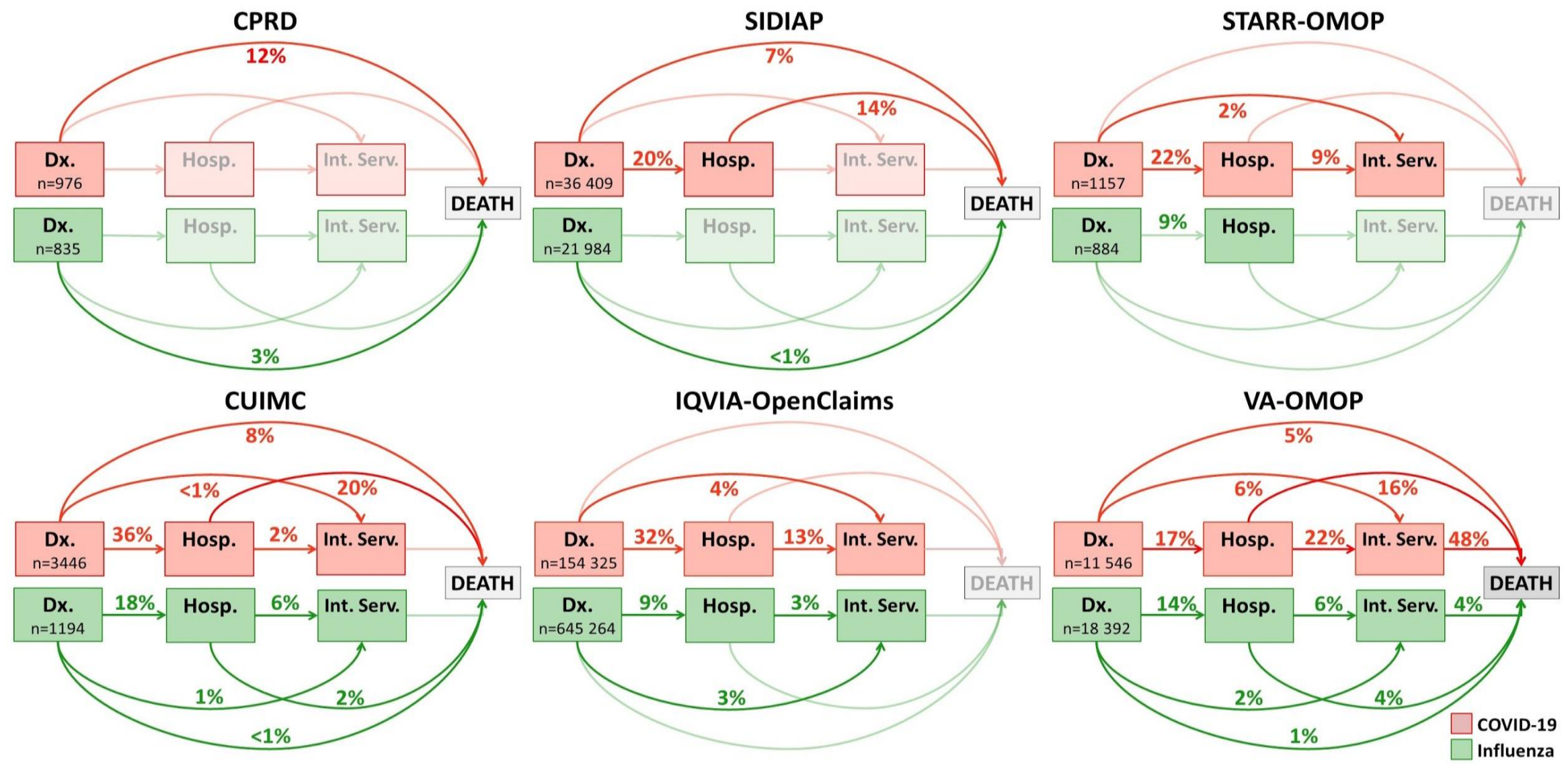

Note: Lighter colours mean data not available.

Abbreviations: COVID-19: Coronavirus Disease 2019; CPRD: Clinical Practice Research Datalink; CUIMC: Columbia University Irving Medical Center; Dx: Diagnosed;

Hosp: Hospitalized; Int Serv: Intensive Services; SIDIAP: Information System for Research in Primary Care; STARR-OMOP: Stanford Medicine Research Data Repository; VA-OMOP: United States Department of Veterans Affairs. 


\section{Table 2: 30-day events in obese and non-obese patients hospitalized with COVID-19}

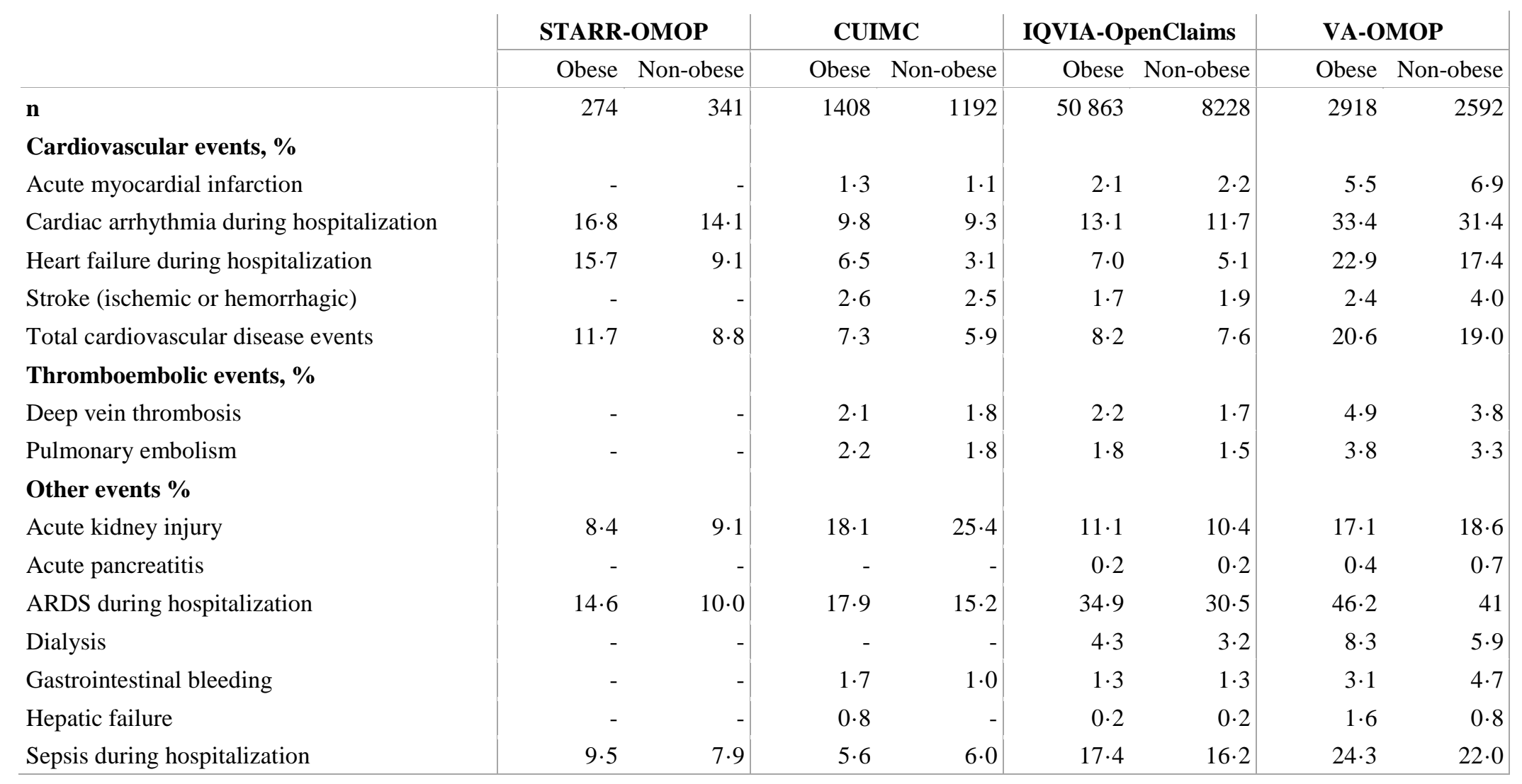

Notes: - data not available or below the minimum cell count required (5 individuals)

Abbreviations: ARDS: Acute Respiratory Distress Syndrome; CUIMC: Columbia University Irving Medical Center; STARR-OMOP: Stanford Medicine Research Data Repository; VA-OMOP: United States Department of Veterans Affairs. 
medRxiv preprint doi: https://doi.org/10.1101/2020.09.02.20185173; this version posted September 3, 2020. The copyright holder for this preprint (which was not certified by peer review) is the author/funder, who has granted medRxiv a license to display the preprint in

It is made available under a CC-BY-NC-ND 4.0 International license.

\section{References}

1 Di Angelantonio E, Bhupathiraju SN, Wormser D, et al. Body-mass index and all-cause mortality: individual-participant-data meta-analysis of 239 prospective studies in four continents. Lancet 2016; 388: 776-86.

2 Moser JAS, Galindo-Fraga A, Ortiz-Hernández AA, et al. Underweight, overweight, and obesity as independent risk factors for hospitalization in adults and children from influenza and other respiratory viruses. Influenza Other Respi Viruses 2019; 13: 3-9.

3 CDC. Similarities and Differences between Flu and COVID-19. Centers Dis. Control Prev. 2020. https://www.cdc.gov/flu/symptoms/flu-vs-covid19.htm (accessed Aug 20, 2020).

4 NHS. Who's at higher risk from coronavirus (COVID-19) - NHS. 2020. https://www.nhs.uk/conditions/coronavirus-covid-19/people-at-higher-risk/whos-athigher-risk-from-coronavirus/ (accessed Aug 20, 2020).

5 Dietz W, Santos-Burgoa C. Obesity and its Implications for COVID-19 Mortality. Obesity 2020; 28: 1005.

$6 \quad$ Finer N, Garnett SP, Bruun JM. COVID-19 and obesity. Clin Obes 2020; 10. DOI:10.1111/cob.12365.

7 Burn E, Tebe C, Fernandez-Bertolin S, et al. The natural history of symptomatic COVID-19 in Catalonia, Spain: a multi-state model including 109,367 outpatient diagnoses, 18,019 hospitalisations, and 5,585 COVID-19 deaths among 5,627,520 people. medRxiv 2020; 109: 2020.07.13.20152454.

8 Williamson EJ, Walker AJ, Bhaskaran K, et al. OpenSAFELY: factors associated with COVID-19 death in 17 million patients. Nature 2020; 584: 430.

9 Garg S, Kim L, Whitaker M, et al. Hospitalization Rates and Characteristics of Patients Hospitalized with Laboratory-Confirmed Coronavirus Disease 2019 - COVID-NET, 14 States, March 1-30, 2020. MMWR Morb Mortal Wkly Rep 2020; 69: 458-64.

10 Petrilli CM, Jones SA, Yang J, et al. Factors associated with hospital admission and critical illness among 5279 people with coronavirus disease 2019 in New York City: Prospective cohort study. BMJ 2020; 369. DOI:10.1136/bmj.m1966.

11 Richardson S, Hirsch JS, Narasimhan M, et al. Presenting Characteristics, Comorbidities, and Outcomes among 5700 Patients Hospitalized with COVID-19 in the New York City Area. JAMA - J Am Med Assoc 2020; 323: 2052-9.

12 Prieto-Alhambra D, Balló E, Coma E, et al. Filling the Gaps in the Natural History of COVID-19: A Cohort Analysis of 121,263 Cases Followed from Primary Care to Admission and/or Death in Catalonia. SSRN Electron J 2020; published online June 17. 
medRxiv preprint doi: https://doi.org/10.1101/2020.09.02.20185173; this version posted September 3, 2020. The copyright holder for this preprint (which was not certified by peer review) is the author/funder, who has granted medRxiv a license to display the preprint in

It is made available under a CC-BY-NC-ND 4.0 International license .

DOI:10.2139/ssrn.3605124.

13 Reilev M, Kristensen KB, Pottegaard A, et al. Characteristics and predictors of hospitalization and death in the first 9519 cases with a positive RT-PCR test for SARSCoV-2 in Denmark A nationwide cohort. medrxiv 2020; : 1-24.

14 GOV.UK. New obesity strategy unveiled as country urged to lose weight to beat coronavirus (COVID-19) and protect the NHS - GOV.UK. GOV.UK. 2020. https://www.gov.uk/government/news/new-obesity-strategy-unveiled-as-country-urgedto-lose-weight-to-beat-coronavirus-covid-19-and-protect-the-nhs (accessed Aug 20, 2020).

15 Voss EA, Makadia R, Matcho A, et al. Feasibility and utility of applications of the common data model to multiple, disparate observational health databases. $J$ Am Med Informatics Assoc 2015; 22: 553-64.

16 Hripcsak G, Duke JD, Shah NH, et al. Observational Health Data Sciences and Informatics (OHDSI): Opportunities for Observational Researchers. In: Studies in Health Technology and Informatics. IOS Press, 2015: 574-8.

17 Herrett E, Gallagher AM, Bhaskaran K, et al. Data Resource Profile: Clinical Practice Research Datalink (CPRD). Int J Epidemiol 2015; 44: 827-36.

18 Del Mar García-Gil M, Hermosilla E, Prieto-Alhambra D, et al. Construction and validation of a scoring system for the selection of high-quality data in a Spanish population primary care database (SIDIAP). Inform Prim Care 2012; 19: 135-45.

19 Datta S, Posada J, Olson G, et al. A new paradigm for accelerating clinical data science at Stanford Medicine. arXiv 2020; published online March 17. http://arxiv.org/abs/2003.10534 (accessed Aug 20, 2020).

20 Observational Health Data Sciences and Informatics. The Book of OHDSI. 2019. https://ohdsi.github.io/TheBookOfOhdsi/ (accessed Aug 20, 2020).

21 Certain Medical Conditions and Risk for Severe COVID-19 Illness | CDC. https://www.cdc.gov/coronavirus/2019-ncov/need-extra-precautions/people-withmedical-conditions.html (accessed Aug 20, 2020).

22 WHO. WHO | Overweight and obesity. World Heal. Organ. 2017. https://www.who.int/gho/ncd/risk_factors/overweight_obesity/obesity_adults/en/ (accessed Aug 20, 2020).

23 Yates T, Razieh C, Zaccardi F, Davies MJ, Khunti K. Obesity and risk of COVID-19: analysis of UK biobank. Prim Care Diabetes 2020. DOI:10.1016/j.pcd.2020.05.011.

24 Mehta P, McAuley DF, Brown M, Sanchez E, Tattersall RS, Manson JJ. COVID-19: consider cytokine storm syndromes and immunosuppression. Lancet. 2020; 395: 1033-4.

25 Falahi S, Kenarkoohi A. Sex and gender differences in the outcome of patients with COVID-19. J Med Virol 2020; : jmv.26243. 
medRxiv preprint doi: https://doi.org/10.1101/2020.09.02.20185173; this version posted September 3, 2020. The copyright holder for this preprint (which was not certified by peer review) is the author/funder, who has granted medRxiv a license to display the preprint in It is made available under a CC-BY-NC-ND 4.0 International license .

26 Kim J, Nam JH. Insight into the relationship between obesity-induced low-level chronic inflammation and COVID-19 infection. Int J Obes 2020; 44: 1541-2.

27 Iannelli A, Favre G, Frey S, et al. Obesity and COVID-19: ACE 2, the Missing Tile. Obes Surg 2020; : 1-3.

28 Lighter J, Phillips M, Hochman S, et al. Obesity in Patients Younger Than 60 Years Is a Risk Factor for COVID-19 Hospital Admission. Clin Infect Dis 2020; 71: 896-7.

29 Divo MJ, Martinez CH, Mannino DM. Ageing and the epidemiology of multimorbidity. Eur Respir J 2014; 44: 1055-68.

30 Simon AK, Hollander GA, McMichael A. Evolution of the immune system in humans from infancy to old age. Proc R Soc B Biol Sci 2015; 282. DOI:10.1098/rspb.2014.3085.

31 Hu F. Social determinants of obesity. Obesity Epidemiology. Oxford University Press, 2009 DOI:10.1093/acprof:oso/9780195312911.001.0001.

32 Milner JJ, Beck MA. The impact of obesity on the immune response to infection. Proc Nutr Soc 2012; 71: 298-306.

33 Belanger MJ, Hill MA, Angelidi AM, Dalamaga M, Sowers JR, Mantzoros CS. Covid19 and Disparities in Nutrition and Obesity. N Engl J Med 2020; : NEJMp2021264.

34 Luzi L, Radaelli MG. Influenza and obesity: its odd relationship and the lessons for COVID-19 pandemic. Acta Diabetol 2020; 57: 759-64.

35 Burn E, You SC, Sena A, et al. Deep phenotyping of 34,128 patients hospitalised with COVID-19 and a comparison with 81,596 influenza patients in America, Europe and Asia: an international network study. medRxiv 2020.

36 Louie JK, Acosta M, Winter K, et al. Factors Associated With Death or Hospitalization Due to Pandemic 2009 Influenza A(H1N1) Infection in California. JAMA. 2009;302(17):1896-1902.

37 Falagas ME, Athanasoulia AP, Peppas G, Karageorgopoulos DE. Effect of body mass index on the outcome of infections: A systematic review: Obesity Comorbidities. Obes Rev 2009; 10: 280-9.

38 Rolfes MA, Flannery B, Chung JR, et al. Effects of Influenza Vaccination in the United States during the 2017-2018 Influenza Season. Clin Infect Dis 2019; 69: 1845-53. 